\title{
Analysis on Approach to Operate Tourism Economy of Hidden Accommodation Industry
}

\author{
Zhiliang Xia \\ Wenzhou Vocational \& Technical College, Wenzhou. 325035 \\ Xia441@sina.com
}

Keywords: hidden accommodation.tour. industry. approach.

\begin{abstract}
The development and status of tourism has been increasingly put emphasis that brings opportunities to the development of hidden accommodation industry and provides good humanistic environment for regional economy. In China, there exist rather rich tour resources in the area and some resources waiting to be developed.Hidden accommodation, as the new "lucky devil" in leisure tour market, has brought about energy and vitality, especially it will become the key attraction to scenic spots during the promotion of tour attractions under the development of hidden accommodation. Hidden accommodation will also become the strongest arms to develop tour zones for the government and developers so as to put forward the coming of regional tour era. Hence, it is necessary to research on the development of regional tourism economy.
\end{abstract}

\section{Status of Hidden Accommodation in Regional Tourism Economy}

Hidden accommodation regional tourism economy is the combination of regional economy and hidden accommodation tourism economy. It is necessary to learn about the connotation of tourism economy for further study on hidden accommodation regional tourism economy. Tourism economy refers to the economic returns coming out of economic interactions between tourists and tourism enterprises as well as between tourism enterprises and relevant enterprises. Tourism economy provides tourists with corresponding diet, accommodation, traffic, tour, shopping, entertainment and other consuming products, while tourists pay off the fee to form the economic band between tourists and regional tourism economy. Hidden accommodation tourism operators occurs some economic connection with other tourism operators or the third party. These economic connection makes up the content of hidden accommodation tourism economy to protect the cultural resources of hidden accommodation, ancient civilization relics and ecological surroundings, so the economic development cannot damage or ruin ancient culture and civilization relics. The government should take measures to coordinate the economic development and the protection of cultural objects and historic relics in hidden accommodation. China's leisure economy mainly relies on holiday tour that is the critical means to attain the development of regional tourism economy.

Take developed countries for example, "diet, accommodation and traffic" takes up 30\% of tourism consumption, "scenic tour" takes up 10\%, "shopping and entertainment” takes up 60\%. In Singapore and China's Hongkong, "scenic tour, shopping and entertainment” takes up $60 \%$ in tour expenditure while "diet, accommodation and traffic" takes up 40\%. The proportion of domestic tour consuming expenditure is that "diet, accommodation and traffic" takes up 75\%-85\% and "scenic tour, shopping and entertainment" takes up 15\%-25\%. Holiday leisure tour is almost the total content of tour. There is the statistics that long-distance traffic takes up 26\%, commodity shopping takes up $22 \%$, accommodation takes up $12 \%$ and tickets of scenic sports takes up $5 \%$ in the holiday tour consumption. Hence, hidden accommodation leisure holiday-spending suits the developing requirements of the era, which is the total trend of tourism development. According to the study of French Tourism Association chairman Philippe - Bonbear: 43\% of profits in hotels, cafés and restaurants has direct connection with tourism. $42 \%$ of airline transport has something to do with tourism, $23 \%$ of railway transport profits, $12 \%$ of vehicles, $8 \%$ in agriculture and $6 \%$ in architecture is relevant to tourism.” And according to Australian authority, tourism is involved in 108 industries 
of 29 economic sections. All of the above reflects the leading role of tourism in regional economic development. As a comprehensive industry, hidden accommodation can completely bring along many other industries to some extent, such as traffic, transportation, goods, real estate, construction, catering industry, shopping, countryside holiday-spending and so on.

\section{Features of Hidden Accommodation Regional Tourism Economy}

In the first three seasons in 2017, per capital disposable income for national inhabitants is 19,342 yuan, which increases by $9.1 \%$ over the same period of last year. The great majority of people's income is continuously rising with increasing disposable time. Therefore, the requirements for tourism will go up and people will have more requirements in physical culture, tour entertainment and other industries. Furthermore, tour frequency and the number of tourists will also go up. The scale of tour group and the time of accommodation will dramatically go up. Facing socialized and intensified development, hidden accommodation industry needs to strengthen tour management model to build up comprehensive, diversified and richness and flexibility of the business model, to improve the competition of hidden accommodation tourism, to establish new tourism system of hidden accommodation, to unify the entertainment leisure and hidden cultural expenditure of hidden accommodation, to develop hidden accommodation tourism and to promote the development of regional economy.

\subsection{Tourism Economy Development Model of Regional Hidden Accommodation}

Generally speaking, the developing models of tourism economy can be divided into super developing model and lagged developing model. From the developing motivation of tourism, the developing models of tourism economy can be divided into market leading developing model and the government leading developing model. From the exploitation value of tourism, the developing models of tourism can be divided into extension developing model and pushing model. American scholars name both operation models to be "value-driven" and "market-driven", which refers to the government leading tour developing model and market self-adjustment developing model. At present, the direction of tourism development is changing into holiday-spending tour from scenic tour. Although scenic tour still takes up marketing percentage, the future developing trend in tourism market is that holiday-spending tour will become the key choice of tourists. The exploitation of hidden accommodation will adopt the industry exploitation aimed at spending holidays to meet tourists participation and entertainment requirements during their trip under the mainstream surroundings of adapting flexible individual tour methods. Abundant recreation activities should be put emphasis to arrange, the service model should be changed to meet tourists' desire for participation and the strong hidden and traditional regional tourism products should be created to enjoy International tourists. Enrich the content and scope of regional tour, completely develop regional tourism economy, study relevant successful cases on regional tourism economy at home and abroad and promote China's regional development of hidden accommodation tourism economy.

\subsection{Factors of Developing Regional Tourism Economy in Hidden Accommodation}

(1) Hidden Cultural Resources

Regional tourism economy of hidden accommodation industry mainly relies on hidden cultural resources. There is no the exploitation of regional tourism economy of hidden accommodation without hidden cultural resources. It covers all of the relevant objects that can attract tourists' attention and natural tourism resources, such as regional climate, geographical landscape, ecological environment and so on. Tourism resources of hidden culture includes local customs of local people, living habits, historic culture and so on. Jansen-Verbeke,Myriam in the Department of Geography at University of Louvain in Belgium participated in the research work on different themes of tourism in abundant relics, culture and urban tour etc., as well as innovative study on dynamic cultural tourism. The exploitation of developing Disneyland is based on different cultures to create a series of attractive cartoon images and to create a world full of dreams, uniqueness, thrill and excitement 
with modern science and technology. There are Mickey Mouse cartoon city, Animal World, World of Fantasy and other facilities in Disneyland. The exploitation of hidden culture can adopt the exploiting model of Disneyland lying in cultural innovation to develop hidden accommodation.

(2)Financing Resources

The exploitation of hidden accommodation regional tourism needs abundant basic facilities and a great sum of money to construct and maintain. Regional tourism cannot be carried out without basic facilities that ought to be invested a lot. The investment of program construction in hidden accommodation tourism is confronting the situations of political surroundings, social surroundings, economic surroundings, legislative surroundings, humanistic surroundings and regional surroundings. Only good basic facilities of tourism and relevant other facilities as well as stable safe political society can be beneficial to the stable growth and blooming of regional economy that makes for raising development capitals. Comprehensively use guiding funds to promote the government and social capital cooperation (PPP) model, which can encourage more enterprises to enter the field of infrastructure construction, public utilities, social undertakings and other people's livelihood, make full use of social capital to participate in construction, purchase of services and businesses Self-financing and other support projects.

(3)Human Resources

The development of regional tourism in hidden accommodation needs the support of knowledge, culture, technology, information and so on. Human resources is the strongest motivation and the most significant resource to develop regional tourism in hidden accommodation. Hidden accommodation tourism is a highly related industry, such as tourism resources development, tourism product design and innovation. To improve the quality and taste of reclusive cultural tourism resources development, you need to have ethnology, folklore, anthropology, culture, economics, among of which the key is to strengthen the cultivation of talents.

\section{Basic Facilities Construction for Hidden Accommodation}

Tourism basic facilities are the total name of setting up various material facilities to suit tourists' requirements during travelling which is also the necessary foundation to develop tourism, mainly including tour restaurants (hotels), tour traffic, different cultural entertainment, physical education, convalescing and other material facilities.

(1) Basic facilities network of traffic transportation

(2) hotel facilities

(3) travel service station

(4) entertainment facilities

(5) catering and shopping environment facilities

The development of global tourism and tourism services require tourism transport network, travel wisdom network, public service system network to be the integration. The construction of a comprehensive development of the structural system needs to improve the road connecting the region's tourist attractions, tourist service centers, tourist toilets , Parking lots, information networks, signage systems and other public services and infrastructure, so that tourists come in, stay, and play well. Infrastructure construction is an important aspect that affects the transformation and upgrading of regional tourism economy. Only by completing infrastructure construction can we attract more tourists and promote better development of the regional tourism industry.

\section{Further Study Tourism Resources of Regional Hidden Culture}

(1)Further study relevant hidden documents and look up hidden academic results and other information at home and abroad to search documents.

(2) Compare and analyze the exploiting models of hidden culture in different regions and countries to provide reference for the developing model of tourism economy in hidden accommodation.

(3) Compare and analyze relevant documents and cases to seek suitable local developing model 
and commercial model of tourism economy in regional hidden accommodation.

(4) To find out the developing model of local regional tourism economy by analyzing relevant industry chains of hidden accommodation and summarizing the features of developing model in regional tourism economy for hidden accommodation.

(5) Flexibly apply the regional developing model of hidden accommodation to provide theoretical basis and practical results for regional development of tourism economy in hidden accommodation.

\section{Conclusion}

Regional tourism economy of hidden accommodation is the important part of national economic development. In the middle of 1980s, China has put forward the concept of regional tourism. The target of study is based on surrounding tour markets to form cooperative regions and to solve the trouble restricting the development of regional tourism in hidden accommodation. Only to integrate the producing elements of regional tourism and to innovate systems,strengthen cooperation in regional tourism, property transactions and environmental protection. Promote the industry-related and industry-spillover effects of the hidden accommodation tourism, lead the development of related industries, reasonably develop the hidden accommodation tourism resources in the regions and create distinctive characteristics of home-grown products. Take advantage of regional recluse culture and utilize various means and ways to find a suitable local development patterns and approaches, take advantage of the natural scenery in the regions and local social culture, history and culture to provide better services for tourists so that the hidden accommodation tourism to promote the healthy development of regional economy and make contributions to developing regional tourism economy.

\section{Acknowledgements}

2018 Zhejiang Province philosophy and social science planning (18NDJC133YB)

\section{References}

[1]C. Lijie and W. Jicheng, The Engineering Properties of the Product Colors. Journal of Packaging Engineering, vol.5. pp.5-6, 2012.

[2]Y.Suyun. Photography and Art. , Huaxia Press, Beijing, 2013.

[3]Z. Haidong and X. Lixin, Tips for Using Digital Cameras Well - Common Problems and Solutions for Digital Photography. Digital Printing, vol.7. pp .10-11. 2013.

[4]E. Heller and H. Eva, Color Culture, Central Compilation Press. Beijing 2011.

[5]K. Bing. Successful Print Advertising Design and Graphic Originality. Journal of Nanjing Art Institute (fine art and design edition), vol.01.pp.3-5. 2014.

[6]Z. Wenbin. Color Settings in Photoshop . Printing Technology r, vol. 25, pp. 36-38, 2014. 